\title{
Evaluation of Ultrasound-Guided Transversus Abdominis Plane Block versus Quadratus Lumborum Block as preemptive analgesia for Inguinal Hernia Repair Surgeries
}
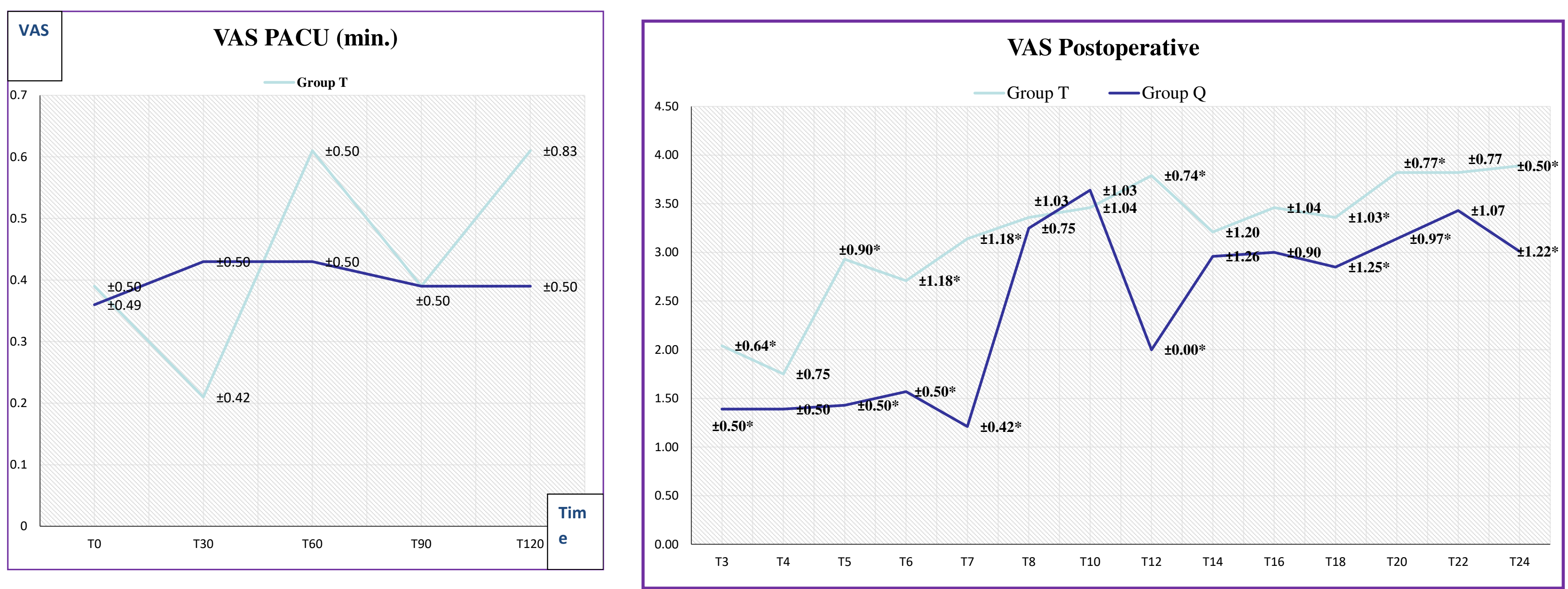

Objective: to evaluate of effect ultrasound-guided transversus abdominis plane block versus quadratus lumborum block as preemptive analgesia.

Background: Ultrasound guided Quadratus lumborum block is a new technique of regional analgesia.

Subjects and Methods: A prospective randomized study was conducted on 56 patients with ASA I or II physical status who were undergoing elective unilateral inguinal hernia repair surgery attended to general surgery department, Faculty of Medicine, Menoufia University during February till December 2018. Patients were divided into: Group $\mathrm{T}$ : included 28 patients who received ultrasound-guided TAP block with $20 \mathrm{ml}$ of bupivacaine $0.25 \%$. Group Q: included 28 patients

who received ultrasound-guided QLB with $20 \mathrm{ml}$ of bupivacaine $0.25 \%$. Full history, routine, physical examination and hear rate, blood pressure was measured.

Results VAS values were at low levels and comparable between the groups $T$ and $Q$. On admission to the PACU and at $(30,60,90$ and 120) minutes postoperative showed lower values in group $Q$ with no significant difference $(P=0.089,0.188,1.00,0.247$ respectively). Then the values started to rise and still comparable up $Q$ at $3,5,6,7,12,18$, 20 and 24 hours postoperatively $(P<0.001,<0.001,<0.001$, $<0.001,<0.001,0.035,0.039,0.043$ respectively). At T 4, 8, $10,14,16,22$, VAS values were comparable between the two studied groups with no significant difference $(P=0.051$, 0.658, 0.520, 0.450, 0.079, 0.121 respectively)..
Amount of fentanyl administered was significantly lower in group Q (P value $<0.05)$.

Nnumber of patients needed additional doses of fentanyl were 10 in group $T$ and 5 in group $Q$ which is significantly lower than group $\mathbf{T}$.

(P value $<0.05$ )

Time for first analgesic request was significantly longer in group Q (P value $<\mathbf{0 . 0 0 1 )}$.

Morphine requirements in the postoperative 24 hours is significantly lower in group Q (P value $<0.001)$

\begin{tabular}{|c|c|c|c|c|c|}
\hline & & $\begin{array}{l}\text { Group T } \\
(\mathbf{N}=28)\end{array}$ & $\begin{array}{c}\text { Group Q } \\
(\mathbf{N}=\mathbf{2 8})\end{array}$ & t. test & $\begin{array}{c}\mathbf{P} \\
\text { value }\end{array}$ \\
\hline \multirow{2}{*}{ Fentanyl use } & $\begin{array}{l}\text { Total amount of fentanyl } \\
\text { used intra } \\
\text { microgram }\end{array}$ & $108.11 \pm 35.97$ & $90.61 \pm 28.79$ & 2.010 & $0.049^{*}$ \\
\hline & $\begin{array}{l}\text { Number of Patient needed } \\
\text { additional doses of fentanyl }\end{array}$ & $10(35.71 \%)$ & $5(17.86 \%)$ & $\begin{array}{c}X^{2}= \\
2.455\end{array}$ & $0.032 *$ \\
\hline \multicolumn{2}{|c|}{ TFAR post-operative (hours) } & $3.75 \pm 0.67$ & $10.21 \pm 2.90$ & 11.498 & $0.000^{*}$ \\
\hline \multicolumn{2}{|c|}{$\begin{array}{l}\text { Morphine requirements }(\mathrm{mg}) \text { in the postoperative } 24 \\
\text { hours }\end{array}$} & $13.86 \pm 2.88$ & $8.21 \pm 2.85$ & 7.379 & $0.000 *$ \\
\hline
\end{tabular}

Conclusions: in patients undergoing Inguinal Hernia Repair Surgeries, Quadratus lumborum block provided more effective intraoperative and postoperative analgesia with less intraoperative fentanyl consumption, less VAS for postoperative pain, a smaller number of patients needed analgesia after surgery and less postoperative morphine consumption 